\title{
Cost analysis of negative-pressure wound therapy versus standard treatment of acute conflict-related extremity wounds within a randomized controlled trial
}

\author{
Andreas Älgå 1,2*iD, Jenny Löfgren ${ }^{3}$, Rawand Haweizy ${ }^{4}$, Khaldoon Bashaireh ${ }^{5,6}$, Sidney Wong ${ }^{7}$, \\ Birger C. Forsberg ${ }^{2}$, Johan von Schreeb ${ }^{2}$ and Jonas Malmstedt ${ }^{1}$
}

\begin{abstract}
Background: Clinical outcomes after negative-pressure wound therapy (NPWT) and standard treatment of conflictrelated extremity wounds are similar. In resource-limited settings, cost affects the choice of treatment. We aimed to estimate treatment-related costs of NPWT in comparison with standard treatment for conflict-related extremity wounds.

Methods: We derived outcome data from a randomized, controlled superiority trial that enrolled adult ( $\geq 18$ years) patients with acute $(\leq 72 \mathrm{~h}$ ) conflict-related extremity wounds at two civilian hospitals in Jordan and Iraq. Primary endpoint was mean treatment-related healthcare costs (adjusted to 2019 US dollars).

Results: Patients were enrolled from June 9, 2015, to October 24, 2018. A total of 165 patients (155 men [93.9\%]; 10 women [6.1\%]; and median [IQR] age, 28 [21-34] years) were included in the analysis. The cost per patient treated with NPWT was $\$ 142$ above that of standard treatment. Overall, results were robust in a sensitivity analysis.
\end{abstract}

Conclusions: With similar clinical outcomes compared to standard care, our results do not support the use of NPWT in routine treatment of conflict-related extremity wounds at civilian hospitals in resource scarce settings.

Trial registration NCT02444598.

Keywords: Trauma, Armed conflict, Wounds, Cost analysis

\section{Introduction}

Extremity wounds and fractures constitute the majority of injuries sustained by civilians during armed conflict [1]. The management of conflict-related injuries is complex and associated with significant challenges [2, 3]. In addition, the resources for healthcare are often limited due to a high burden of disease and injury, and low health

\footnotetext{
*Correspondence: andreas.alga@ki.se

${ }^{1}$ Department of Clinical Science and Education, Södersjukhuset, Karolinska Institutet, Sjukhusbacken 10, 11883 Stockholm, Sweden

Full list of author information is available at the end of the article
}

system resilience [4]. Negative-pressure wound therapy (NPWT) includes covering the wound and applying a negative pressure and has been used in wound care for more than two decades [5]. In recent years, the technique has been introduced in the treatment of acute injuries sustained in armed conflict despite the weak evidence supporting NPWT as an effective means of promoting wound healing [6]. Data on costs for conflict-related wound treatment are scarce.

In a randomized controlled trial, we compared NPWT and standard treatment of conflict-related extremity wounds [7]. We did not find any superior clinical original author(s) and the source, provide a link to the Creative Commons licence, and indicate if changes were made. The images or other third party material in this article are included in the article's Creative Commons licence, unless indicated otherwise in a credit line to the material. If material is not included in the article's Creative Commons licence and your intended use is not permitted by statutory regulation or exceeds the permitted use, you will need to obtain permission directly from the copyright holder. To view a copy of this licence, visit http://creativecommons.org/licenses/by/4.0/. The Creative Commons Public Domain Dedication waiver (http://creativeco mmons.org/publicdomain/zero/1.0/) applies to the data made available in this article, unless otherwise stated in a credit line to the data. 
outcomes for NPWT compared to standard treatment [8]. The proportion who reached the primary endpoint, wound closure by day five, was $49 \%(n=41 / 83)$ in the NPWT group and $60 \%(n=49 / 82)$ in the standard treatment group (risk ratio 0.83 , 95\% confidence interval $0.62-1.09, p=0.183)$. The clinical outcomes of the trial have been published in full elsewhere [8]. The aim of the present study was to determine the treatmentrelated costs of NPWT compared to the costs of standard treatment.

\section{Methods}

This is a health economic evaluation of a randomized controlled trial comparing outcomes from conflictrelated extremity wound treatment using NPWT and standard treatment (NCT02444598) [7]. The study findings are reported in accordance with the Consolidated Health Economic Evaluation Reporting Standards (CHEERS) guidelines [9].

\section{Trial procedures}

The design and clinical outcomes of the randomized controlled trial have been described in detail elsewhere $[7,8]$. Briefly, 165 adult ( $\geq 18$ years) patients with acute $(\leq 72 \mathrm{~h})$ conflict-related extremity wounds were enrolled from June 9, 2015, to October 24, 2018, at two civilian hospitals in Jordan and Iraq. Participants were randomly assigned to NPWT $(n=83)$, involving a commercial NPWT device with a continuous negative pressure of $125 \mathrm{~mm} \mathrm{Hg}$, or standard treatment $(n=82)$, involving wound dressings with non-adhesive sterile gauze covered with a bandage. Dressings were changed in the operating theatre every three to five days, in accordance with the International Committee of the Red Cross war surgery protocol [10]. The primary outcome was wound closure by day five. Data on wound closure were collected at each dressing change, at hospital discharge, and at days 14 and 30 following the day of randomization. Wound closure was defined as closure by suture, flap, or split-thickness skin graft. A coprimary endpoint, net clinical benefit, was used, defined as a composite of wound closure by day five, and freedom from any bleeding, wound infection, sepsis, or amputation of an index limb. Health outcome data from both study sites were used for the present study.

\section{Cost analysis}

The cost analysis was undertaken from the perspective of the healthcare provider [11]. Costs were either related to surgeries or to the care given on the ward and included the following items: medicines and materials, staff costs, overhead costs, and capital costs (Table 1). A surgical procedure was defined as any intervention that occurred in the operating theatre, including wound dressing changes. Wound dressing changes were not performed on the ward. The cost per surgical procedure was calculated based on the total number of surgeries per year. Costs for postoperative care on the ward were calculated as cost per $24 \mathrm{~h}$, based on the yearly costs for all admitted patients divided by the yearly number of patient-days on the ward.

The Iraqi site, where information was readily available to the study team, provided cost data. During 2017, the Iraqi hospital provided a total of 6169 patient days and 2210 surgeries, exclusively for patients with acute conflict-related injuries. Costs for the treatment of chronic wounds (defined as non-closure within 30 days) were not included in the analysis. All NPWT equipment was bought for the purpose of this study. Local costs were converted to average 2019 US dollars.

\section{Medicines and materials}

Mean cost for single-use items (e.g., dressing materials and NPWT sponges) used for dressing changes (NPWT and standard treatment) as well as mean cost for medicines was calculated based on the amount used during the surgical procedures. Data were provided by the participating surgeons and nurses.

\section{Staff costs}

Standard staffing in the operating theatre was one surgeon, one anesthesiologist, one anesthesiologist assistant, and one perioperative nurse. Standard staffing on the ward was one nurse per four patient beds. Data were obtained from the hospital pay roll.

\section{Overhead costs}

Overhead costs included costs for water, electricity, transportation, and administration. Data were extracted from the hospital's end-of-year report. The overhead costs applied to the treatment of the study patients were based on the patients' proportional use of hospital space (operating theatre and the ward).

\section{Capital costs}

Capital costs were incurred for hospital buildings (operating theatre and the ward) and for equipment used for the surgical procedures and on the ward. For this study, the value of the hospital buildings was estimated based on the income if the area occupied by the buildings had been used for land lease. The capital cost of the operation theatre and the ward was estimated by multiplying the capital cost of each building by the proportion of the total surface area allocated to each of these units. To calculate the capital cost per surgery, the capital cost of the operating theatrewas divided by the annual number 


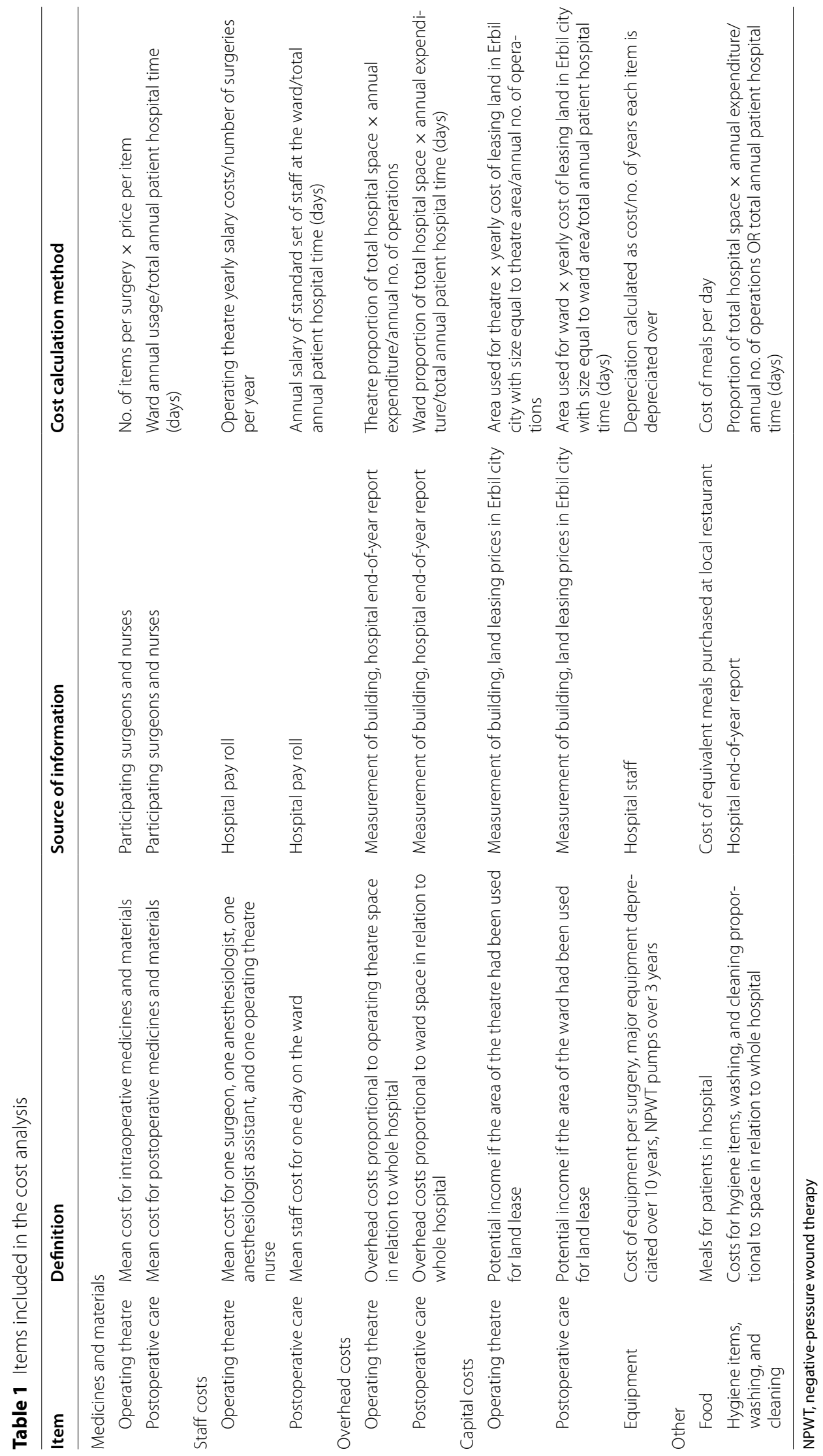


of surgeries. The capital cost per day spent at the hospital was calculated by dividing the capital cost of the ward by the total number of patient days on the ward. Major equipment, such as the operating table and autoclave, was depreciated over 10 years. NPWT pumps were depreciated over three years.

\section{Other}

Other costs included costs for food, hygiene items, washing, cleaning, and waste management. Data were extracted from the hospital's end-of-year report.

\section{Sensitivity analysis}

To assess the robustness of the findings, a sensitivity analysis was performed. The surgical productivity level was modified by $-20 \%$ and by $+20 \%$, and staff costs were modified by $-50 \%$ and by $+50 \%$. To assess the effects of a rural hospital setting, rental costs were modified by $-50 \%$. The cost for NPWT pumps used in this study was lower than standard costs in high-resource settings. Thus, the capital cost for the NPWT pumps was modified by $+100 \%$.

\section{Statistical analysis}

We analyzed data using $R$ version 3.5.0 software [12].

\section{Results}

A total of 165 patients (155 men [93.9\%]; 10 women [6.1\%]; and median [IQR] age, 28 [21-34] years) were included in the study. Randomization and analysis are depicted in Fig. 1. The groups were well balanced in baseline characteristics.

\section{Costs}

The cost per surgery was $\$ 329$ in the NPWT group and $\$ 250$ in the standard treatment group. The cost per day spent at the hospital was \$116 and \$109 in the NPWT and standard treatment groups, respectively. The mean patient cost for the full hospital period was $\$ 3118$ in the NPWT group and \$2976 in the standard treatment group (Table 2). Consequently, the use of NPWT was associated with an additional $\$ 142(5 \%)$ per treated patient compared to standard treatment (Fig. 2).

\section{Sensitivity analysis}

Table 3 shows a sensitivity analysis of mean patient costs using NPWT and standard treatment. While some changes did occur with respect to the mean difference in cost, patients allocated to NPWT had consistently higher costs.

\section{Discussion}

In this health economic evaluation of a pragmatic, randomized, controlled superiority trial in patients with acute conflict-related extremity wounds, the overall cost for treatment was higher in the NPWT group compared to the standard treatment group. Our previous results showed no significant differences in clinical outcomes for NPWT compared to standard treatment in this setting [8]. The present study adds information on treatment costs for civilians with conflict-related wounds when managed using NPWT and standard treatment.

Health economic evaluation is essential when considering implementation of new treatment methods, particularly in resource-limited settings [13]. Despite NPWT being a costly mode of treatment, it has been

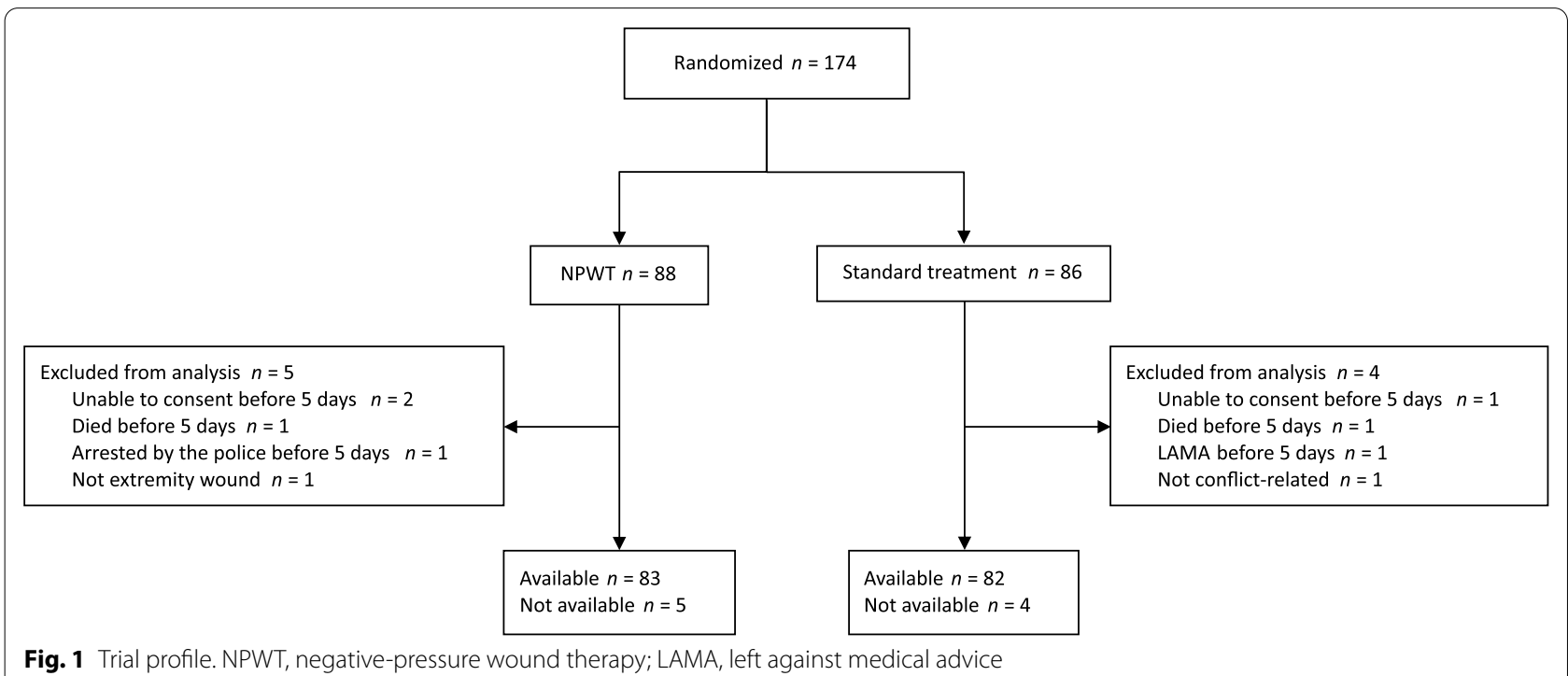

Fig. 1 Trial profile. NPWT, negative-pressure wound therapy; LAMA, left against medical advice 


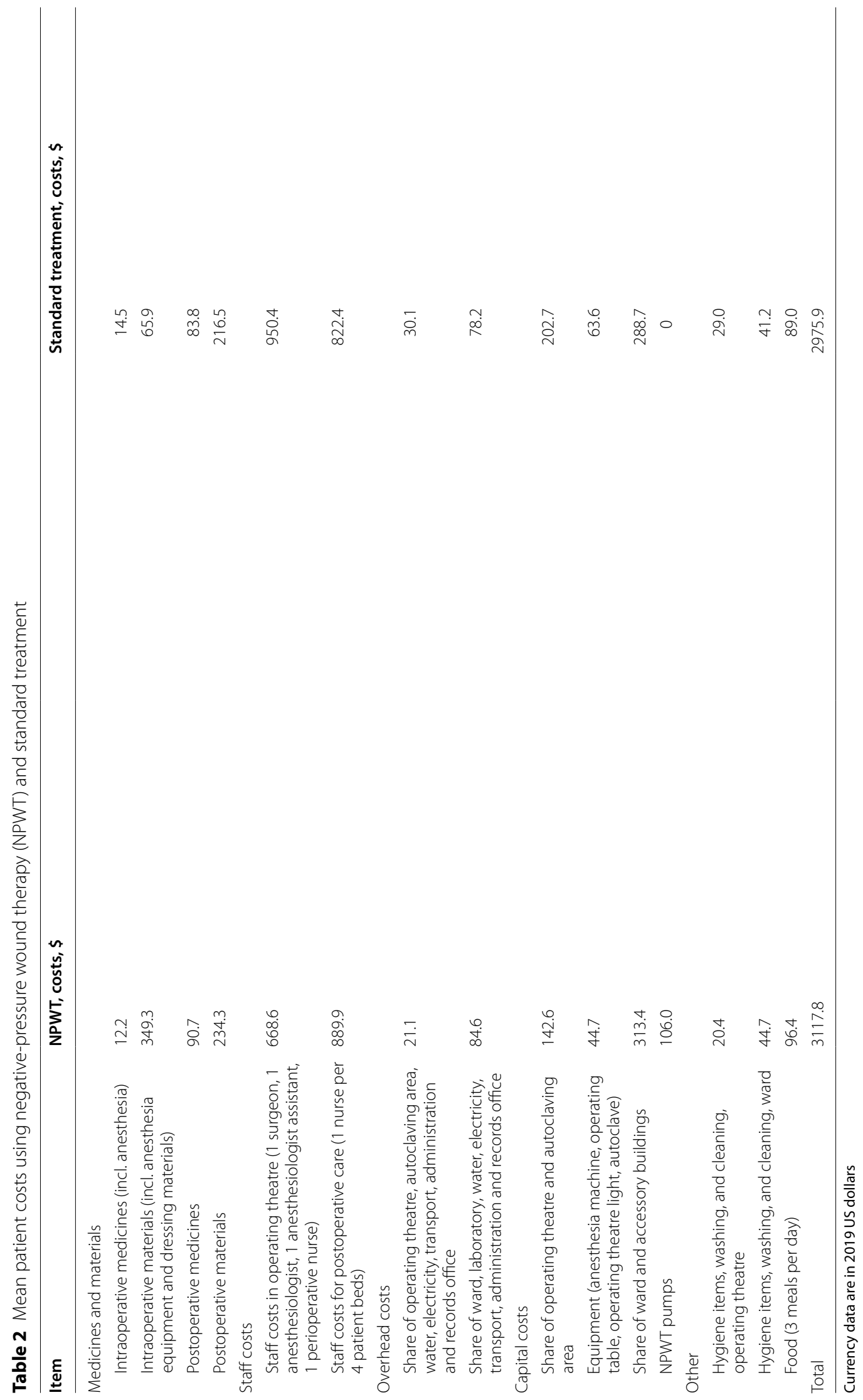




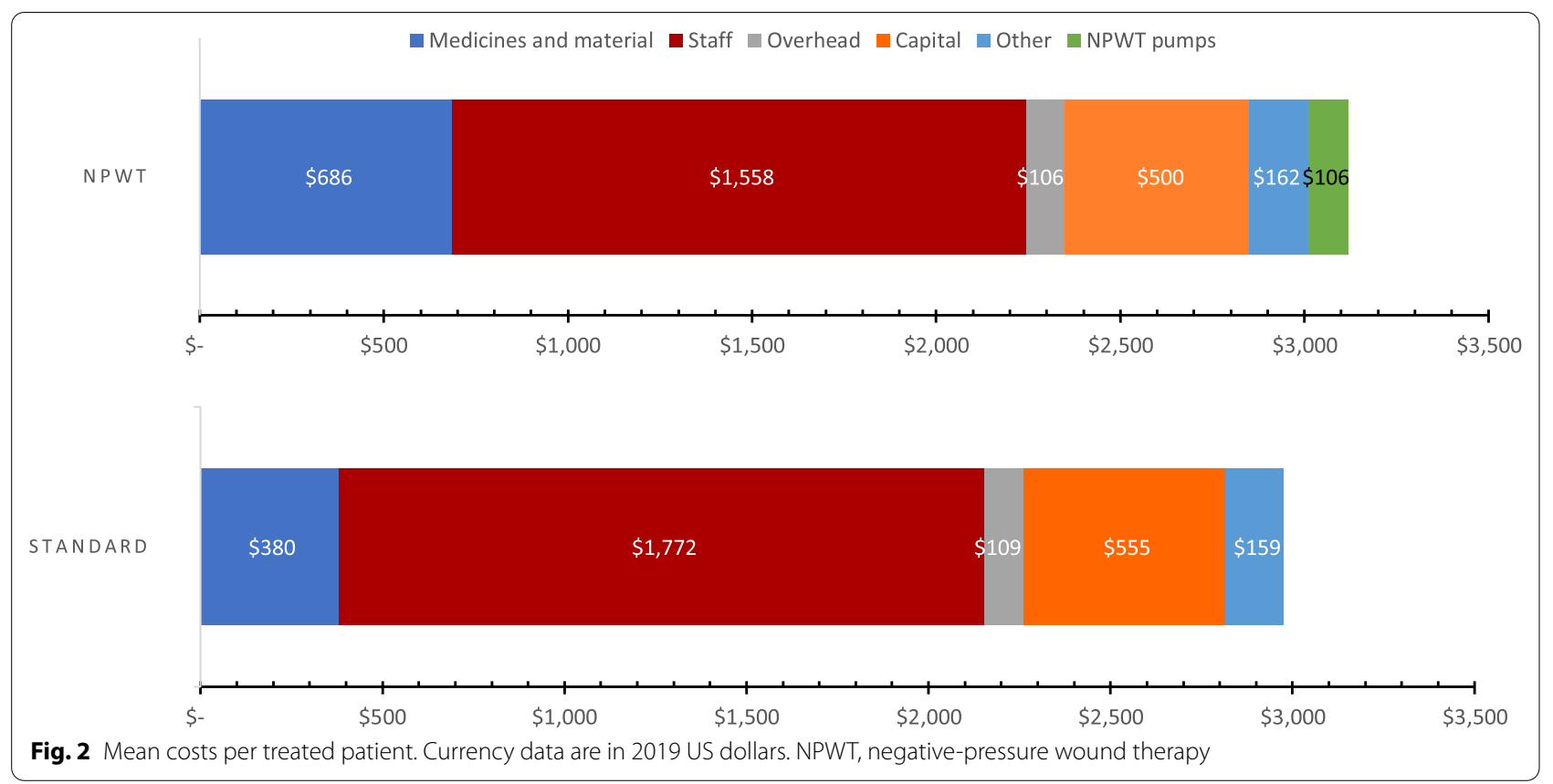

Table 3 Sensitivity analyses of mean patient costs using negative-pressure wound therapy (NPWT) and standard treatment

\begin{tabular}{lllc}
\hline & NPWT & Standard treatment & Incremental cost (\%) \\
\hline $\begin{array}{l}\text { Baseline } \\
\text { Sensitivity analyses }\end{array}$ & 3118 & 2976 & $142(5 \%)$ \\
$\begin{array}{l}\text { Productivity level } \\
\quad 0 \%\end{array}$ & 3756 & & $78(2 \%)$ \\
$\quad 120 \%$ & 2692 & 3678 & $184(7 \%)$ \\
Staff costs & & 2508 & $248(12 \%)$ \\
$\quad 50 \%$ & 2321 & & $36(1 \%)$ \\
$\quad 30 \%$ & 3915 & 2073 & $160(6 \%)$ \\
Hospital location, rural (rental costs 50\%) & 2889 & 3879 & $248(8 \%)$ \\
\hline
\end{tabular}

Currency data are in 2019 US dollars

widely implemented without robust evidence of effectiveness nor of cost-effectiveness [14]. Of the few published randomized controlled trials on NPWT for traumatic injuries, only one included an economic evaluation [6]. Petrou et al. assessed NPWT in 460 patients with open lower limb injuries in a high-income setting and could not show any cost-effectiveness benefit for NPWT compared to standard treatment [15]. Healthcare in all contexts entails choices about resource allocation, and interventions should be guided by public health considerations. This requires maintained quality of care, guaranteed effectiveness of treatment, and justification of costs. Introducing treatment methods that increase costs, without clinical benefit, is not justifiable, especially not in settings where resources are scarce.

Limitations to this study include the use of assumptions to calculate costs, and the use of proxies in the absence of cost information, which might have introduced bias. In addition, there is a risk of facility bias as cost data could only be retrieved from one of the two study hospitals. However, the absence of information often represents a challenge to health economic evaluations, and assumptions are therefore commonly used. Costs were calculated using the same methods for both treatment groups, and therefore, we believe the cost comparison is reliable. As costs depend on hospital setting, the cost differences 
between NPWT and standard treatment will vary. However, the sensitivity analysis indicates robustness of our results and describes a variation of costs in several different scenarios, which is advantageous for policy and decision-making. The real-world setting at acute surgery hospitals that do not perform elective surgery may allow for generalization to similar populations of injured civilians. The pragmatic study design increases the external validity, which generally is a concern with health economic evaluations based on randomized trials [16].

To our knowledge, this is the first health economic evaluation of NPWT for traumatic wounds carried out in a resource-limited setting. Although we found no support for the use of NPWT, the technique may serve purposes not assessed in this study, such as improving the quality of life by affecting patients' discomfort, woundassociated pain, and sleep quality. In addition, the role for NPWT in the treatment of chronic wounds and in patients treated with open abdomen technique still needs to be defined [17-19]. These areas are all in need of further investigation.

\section{Conclusions}

Among patients with acute conflict-related extremity wounds treated at two civilian hospitals, NPWT did not decrease costs nor improve health outcomes, as compared to standard treatment. Wide-scale introduction of NPWT for the management of conflict-related extremity injuries cannot be recommended.

\section{Abbreviations \\ CHEERS: Consolidated Health Economic Evaluation Reporting Standards; IQR: Interquartile range; NPWT: Negative-pressure wound therapy.}

\section{Acknowledgements}

We acknowledge the contribution of the Médecins Sans Frontières Sweden Innovation Unit, and all the research associates at the participating sites, in particular Murad Alrawashdeh, Mustafa Gaylan, and Jasim Muhamad for collecting data.

\section{Authors' contributions}

$A \ddot{A}, J M, J v S, J L, B F$, and SW were responsible for the design of the trial. A $A ̈$ initiated and oversaw the trial at the study sites. $\mathrm{RH}$ contributed to patient recruitment, treatment, and data collection. KB provided administrative support. Ä̈, $J L, B F$, and $J M$ did the data analysis. AÄ wrote the first draft. JM, JVS, JL, SW, RH, $\mathrm{BF}$, and $\mathrm{KB}$ were major contributors in writing the manuscript. All authors read and approved the final manuscript.

\section{Funding}

Open access funding provided by Karolinska Institute. This work was supported by the Stockholm County Council (ALF 20160207), the Swedish National Board of Health and Welfare (10.1-30118/2019), and Médecins Sans Frontières. No companies were involved in any part of the trial, nor did any companies contribute funding. The funders had no role in study design, data collection, data analysis, data interpretation, or writing of the report.

\section{Availability of data and materials}

Our ethics approval limits us to the publication of results at the aggregate level only, precluding us from publishing individual-level patient data. Data underlying the results are available for researchers who meet the criteria for access to confidential data. Data will be available with publication and for 10 years subsequently. Proposals should be directed to andreas.alga@ki.se.

\section{Declarations}

\section{Ethics approval and consent to participate}

This health economic analysis was part of a clinical trial which received ethical approval from the Ethics Review Committee of the Jordan Ministry of Health (MOH REC 150037), the Ethics Review Board of Médecins Sans Frontières (ID 1520), the Research Ethics Committee, Kurdistan Regional Government in Iraq (2:10 6/3/2017), and the Swedish Ethical Review Authority (2019-01975). All participants provided written informed consent.

\section{Consent for publication}

Not applicable.

\section{Competing interests}

The authors declare that they have no competing interests.

\section{Author details}

${ }^{1}$ Department of Clinical Science and Education, Södersjukhuset, Karolinska Institutet, Sjukhusbacken 10, 11883 Stockholm, Sweden. ${ }^{2}$ Department of Global Public Health, Karolinska Institutet, 17177 Stockholm, Sweden. ${ }^{3}$ Department of Molecular Medicine and Surgery, Karolinska Institutet, 17177 Stockholm, Sweden. ${ }^{4}$ College of Medicine, Hawler Medical University, 40/0112 Erbil, Iraq. ${ }^{5}$ Department of Special Surgery, Jordan University of Science and Technology, 22110 Irbid, Jordan. ${ }^{6}$ Medical Faculty, Yarmouk University, Irbid 21163, Jordan. ${ }^{7}$ Médecins Sans Frontières, Operational Centre Amsterdam, Plantage Middenlaan 14, 1018 DD Amsterdam, The Netherlands.

Received: 7 December 2021 Accepted: 30 January 2022

Published online: 10 February 2022

\section{References}

1. Aboutanos MB, Baker SP. Wartime civilian injuries: epidemiology and intervention strategies. J Trauma Acute Care Surg. 1997;43:719-26.

2. Älgå A, Herzog KK, Alrawashdeh M, et al. "Reality rarely looks like the guidelines": a qualitative study of the challenges hospital-based physicians encounter in war wound management. Scand J Trauma Resusc Emerg Med. 2018;26:52.

3. Älgå A, Wong S, Shoaib M, et al. Infection with high proportion of multidrug-resistant bacteria in conflict-related injuries is associated with poor outcomes and excess resource consumption: a cohort study of Syrian patients treated in Jordan. BMC Infect Dis. 2018;18:233.

4. Guha-Sapir D, van Panhuis WG. The importance of conflict-related mortality in civilian populations. Lancet. 2003;361:2126-8.

5. Apelqvist J, Willy C, Fagerdahl AM, et al. EWMA Document: Negative Pressure Wound Therapy. J Wound Care. 2017;26:S1-154.

6. Iheozor-Ejiofor Z, Newton K, Dumville JC, et al. Negative pressure wound therapy for open traumatic wounds. Cochrane Database Syst Rev. 2018;7:CD012522.

7. Älgå A, Wong S, Haweizy R, et al. Negative-pressure wound therapy versus standard treatment of adult patients with conflict-related extremity wounds: protocol for a randomized controlled trial. JMIR Res Protoc. 2018;7:e12334.

8. Älgå A, Haweizy R, Bashaireh K, et al. Negative pressure wound therapy versus standard treatment in patients with acute conflict-related extremity wounds: a pragmatic, multisite, randomised controlled trial. Lancet Glob Health. 2020;8:e423-9.

9. Husereau D, Drummond M, Petrou S, et al. Consolidated Health Economic Evaluation Reporting Standards (CHEERS) statement. BMJ. 2013;346:f1049.

10. Giannou C, Baldan M. War surgery, vol. 1. London: The Royal College of Surgeons of England; 2010.

11. Drummond MF, Sculpher MJ, Claxton K, et al. Methods for the economic evaluation of health care programmes. Oxford: Oxford University Press; 2015. 
12. Core Team R. Vienna, Austria. R Foundation for Statistical Computing. 2018.

13. Leech AA, Kim DD, Cohen JT, et al. Are low and middle-income countries prioritising high-value healthcare interventions? BMJ Glob Health. 2020;5(2):e001850.

14. Peinemann F, Labeit A. Negative pressure wound therapy: a systematic review of randomized controlled trials from 2000 to 2017. J Evid Based Med. 2019;12:125-32.

15. Petrou S, Parker B, Masters J, et al. Cost-effectiveness of negative-pressure wound therapy in adults with severe open fractures of the lower limb: evidence from the WOLLF randomized controlled trial. Bone Joint J. 2019;101:1392-401.

16. Berger ML, Sox H, Willke RJ, et al. Good practices for real-world data studies of treatment and/or comparative effectiveness: recommendations from the joint ISPOR-ISPE Special Task Force on real-world evidence in health care decision making. Pharmacoepidemiol Drug Saf. 2017;26:1033-9.

17. Dumville JC, Webster J, Evans D, et al. Negative pressure wound therapy for treating pressure ulcers. Cochrane Database Syst Rev. 2015.

18. Dumville JC, Land L, Evans D, et al. Negative pressure wound therapy for treating leg ulcers. Cochrane Database Syst Rev. 2015.

19. Cirocchi $R$, Birindelli $A$, Biffl $W L$, et al. What is the effectiveness of the negative pressure wound therapy (NPWT) in patients treated with open abdomen technique? A systematic review and meta-analysis. J Trauma Acute Care Surg. 2016;81:575-84.

\section{Publisher's Note}

Springer Nature remains neutral with regard to jurisdictional claims in published maps and institutional affiliations.

Ready to submit your research? Choose BMC and benefit from:

- fast, convenient online submission

- thorough peer review by experienced researchers in your field

- rapid publication on acceptance

- support for research data, including large and complex data types

- gold Open Access which fosters wider collaboration and increased citations

- maximum visibility for your research: over $100 \mathrm{M}$ website views per year

At BMC, research is always in progress.

Learn more biomedcentral.com/submissions 